\title{
CrimeID: Towards Crime Prevention and Community Safety in Indonesia using Mobile and Web Technology
}

\author{
https://doi.org/10.3991/ijim.v13i09.10172 \\ Yohanes Sigit Purnomo W.P. ${ }^{\left({ }^{凶}\right)}$, Theresia Devi Indriasari, Kusworo Anindito, \\ Yoshua Andrean, Jaka Galih Prasetyo \\ Universitas Atma Jaya Yogyakarta, Yogyakarta, Indonesia \\ sigit.purnomo@uajy.ac.id
}

\begin{abstract}
The rate of crime incidence in Indonesia is quite high. Some efforts to prevent crime and to create community safety have been already conducted. However, the information technology has not been implemented yet. CrimeID could be a technology tool for both individual and collective crime prevention. The citizen could participate individually as a crowd to annotate the crime data from news article through the crowdsourcing platform using gamification concept. The collected data could be used to raise the awareness among community members of the crime that happens surrounding them by using the location-aware system.
\end{abstract}

Keywords - Crime prevention, community safety, crowdsourcing, gamification, location-aware

\section{Introduction}

Indonesian Police registration data in Criminal Statistics 2016 Report, stated that the incidence of crimes in Indonesia during the period 2013-2015 tends to fluctuate [1]. The incidence is about 341 thousand cases in 2013, decreased to about 325 thousand cases in 2014, and increased to approximately 353 thousand cases by 2015 . This report also stated that the crime rate during the period 2013-2015 for every 100 thousand people estimated at 140 people in 2013, 131 people in 2014, and 140 people by 2015. The data in this report obtained from two main sources. First, criminal data that collected by the State Police of Republic of Indonesia (administrative-based data). Second, criminal data sourced from the National Socioeconomic Survey and Village Potential Statistics produced by the Indonesian Central Bureau of Statistics (surveybased data).

The crimes incidence of and crime rate in Indonesia mention above are quite high. Crime prevention and community safety efforts already conducted. The Indonesian Government has already concerning about crime prevention as part of peace and order in society as stated in Law No. 2/2002 about Indonesian Police [2]. One of the implementations of this law is that Indonesian Police Chief release a regulation No. 23/2007 about neighborhood security system (SISKAMLING). SISKAMLING have two functions [3]. First, it works as a facility for citizens to meet their needs of feeling 
safe in their living environment. Second, it counters threats and disruption occurred in their residence by pre-emptive action to countermeasures against phenomena and situations that can be categorized as criminogenic correlative factor.

Nowadays, crime prevention and police performance improvement could be developed by using new innovation in technology [4]. The use of technological innovation in the crime prevention could be implemented on the hard or soft technology. Hard technology includes the use of materials or equipment's that can be used to prevent crime such as CCTV cameras [5] [6] and metal detector [7]. Soft technologies are used to prevent crime by utilizing information generated by software as well as the latest techniques in computer data processing, for example, geographic information system [8] [9] [10]. In Indonesia, the technological innovation for crime prevention mostly still use the hard technology like CCTV. There is still no accessible crime prevention information system that are available for the citizens.

CRIMEID aims to be a soft technology that could help the crime prevention and community safety program. CRIMEID will provide more detailed crime data in Indonesia, that it can be used for various purposes like crime prevention information system and alerting people in the area with the high crime rate. The data collected includes crime event, crime location, crime victim, crime suspect, and crime status. The news article as a source of the crime data will be attached to the crime data for the verification and validation process.

There are three important things that will be discussed in this paper. First is how to develop a crowdsourcing platform to annotate crime data based on articles available on online news sites. Second is how to develop a mechanism in the form of gamification so it can make people interested to participate in the process of annotating crime data through the platform. Third is how to use the collected data to support crime prevention and community safety program through open data and location-aware applications.

\section{Citizen-led Crime Prevention}

Bjørgo, 2016, in his book, "Preventing Crime: A Holistic Approach" has developed a complete model for crime prevention that has nine crime prevention mechanisms as the center of the model [11]. These mechanisms are grouped logically into three groups, first is a mechanism to prevent criminal acts from occurring, second is a mechanism to handle criminal acts that occur, and the last is a mechanism to prevent criminal acts from happening again. The first group includes building moral barriers, reducing the emergence of new criminals, general prevention, proactive inability, disruption, and protecting targets that are prone to crime. The second group includes reactive incapacitation and reducing harm. The last group includes specific deterrence, proactive incapacitation, reducing benefits, and rehabilitation.

Both of the citizens and criminal justice system are responsible for crime prevention. V. Roberts \& Hastings, 2012, found that most of the people trust that the main task for preventing crime is outside the criminal justice system [12]. According to Madero-Hernandez, et al., 2016, crime prevention behaviors that involve the citizens 
could be individualistic or collective [13]. The individualistic crime prevention is associated with the victimization experience and safety perception such as fear or crime. Collective crime prevention is more associated with the function of the community context, for example, informal social control. Individual crime prevention behavior orientation is to protect persons and their property from crime. Collective crime prevention behavior goal is to protect the entire neighborhoods to reduce victimizations in the neighborhoods. Our proposed systems (CrimeID) would be categorized as a citizen-led crime prevention system.

\section{CrimeID: A Crowdsourcing Platform, Gamification and Location-aware System for Indonesian Crime Data}

Towards crime prevention and community safety, we propose a system consisting of three applications. First, a crowdsourcing application to annotate criminal data in Indonesia taken from a local online news site. Second, open data application that provides processed crime data so it can be used by the third parties. Third, a locationaware application that provides users with alerts when entering crime-prone areas as well as application to display crime statistics and crime news. The architecture of CrimeID system is shown in Figure 1.

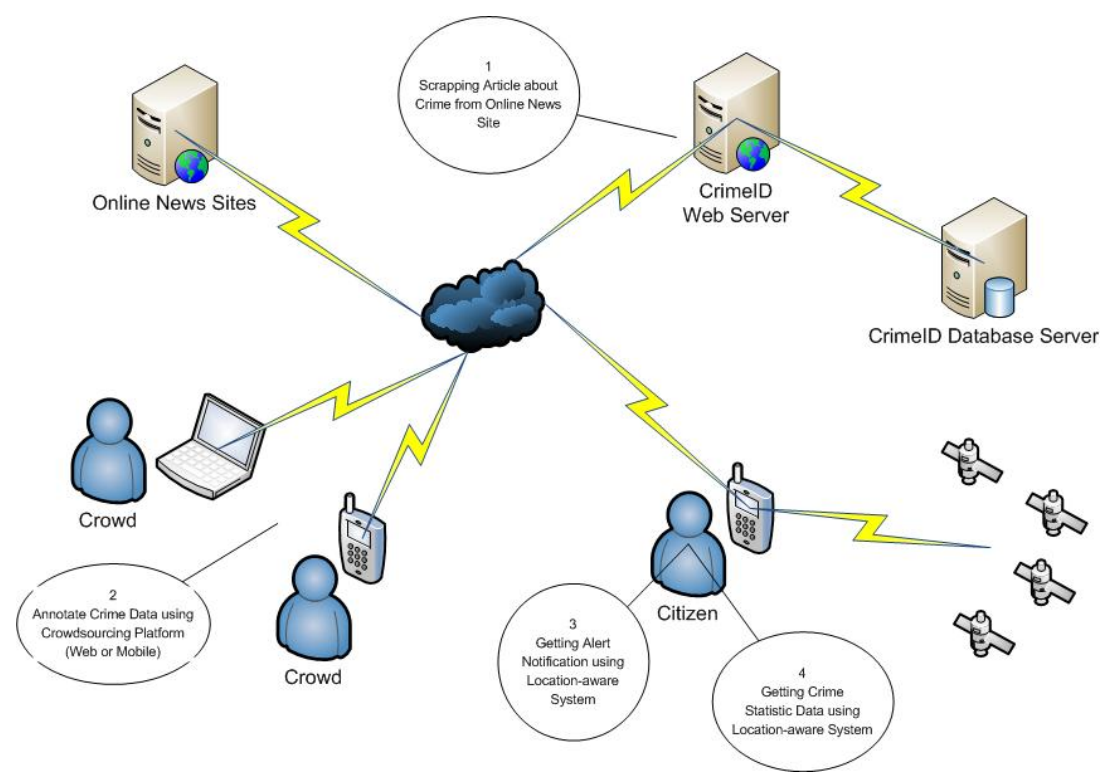

Fig. 1. The Architecture of CrimeID System. 


\subsection{Developing the crowdsourcing platform}

The data in Criminal Statistics 2016 Report [1] is presented in the form of summary per province in Indonesia (Figure 2) and the data do not inform the details of each crime that happened during that period. This could be an obstacle for the parties who want to do further research related to the crime aspect like crime prevention and community safety. For example, efforts to raise awareness about the risk level of the population exposed to crime through an early warning system that uses location-based would be inaccurate. The scope of province level geocodes as based for calculation is too broad compared to the real geocode coordinate. To address this problem, the detailed crime data, especially the location of crime were needed.
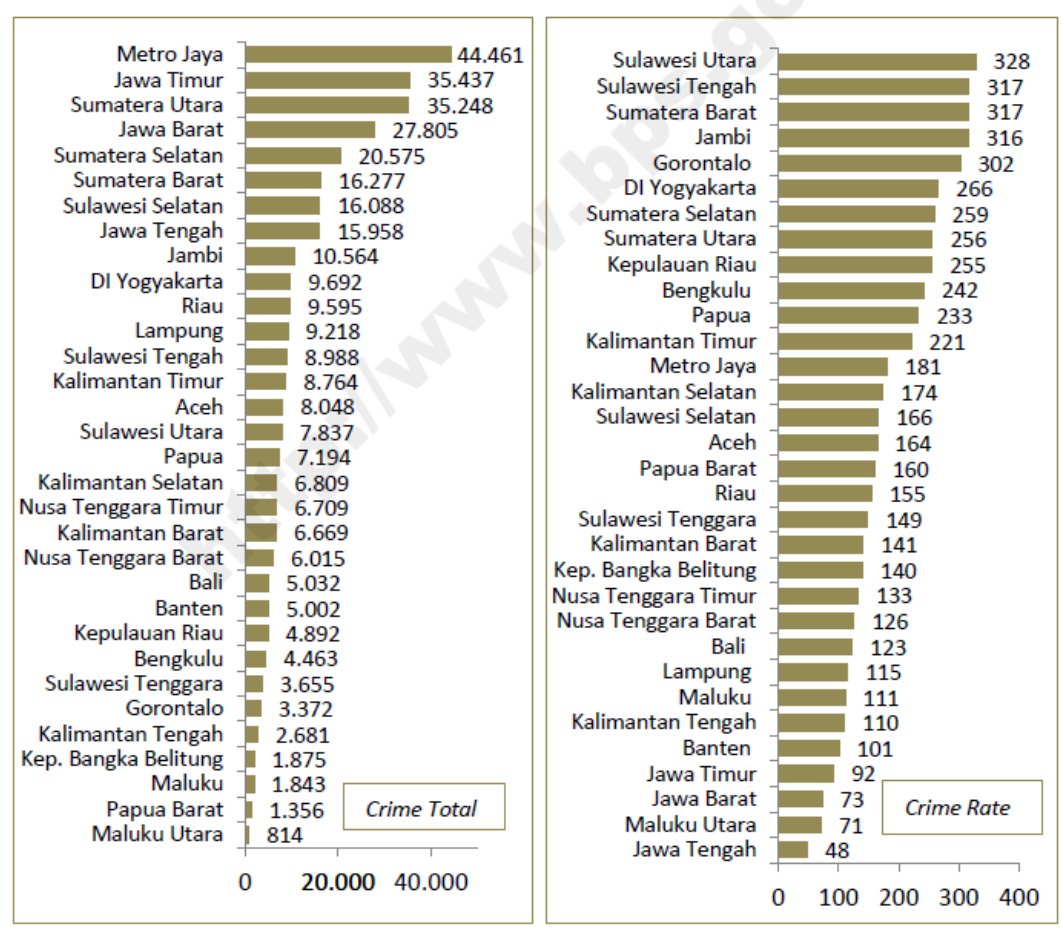

Fig. 2. Summary of Indonesian Crime Data during 2013-2015 (Source: [1])

Information about crime in Indonesia is currently spread in various local online news sites that can be accessed by the public. This information cannot be directly used to raise awareness about the risk level of the population exposed to crime. News about the crime must be gathered first before it can be processed. After the news is collected, the next step is to annotate the crime data in accordance with the level of details of the required data. Crowdsourcing would be a proper solution because it depends on the community to perform costly and time-consuming tasks if it is compared to the traditional approach [14]. 
Developing a crowdsourcing should concern with its main pillars namely the crowdsourcer, the crowd, the crowdsourced task and the crowdsourcing platform [15]. We define the configuration of our crowdsourcing system as shown in Table 1.

Table 1. Crowdsourcing Configuration for CrimeID

\begin{tabular}{|l|l|}
\hline \multicolumn{1}{|c|}{ Crowdsourcing Pillar } & \multicolumn{1}{c|}{ CrimeID Configuration } \\
\hline The crowdsourcer & Researcher \\
\hline The crowd & Indonesian citizens (volunteer-based) \\
\hline The crowdsourced task & $\begin{array}{l}\text { Annotate the crime data from a published crime news and reporting invalid } \\
\text { data }\end{array}$ \\
\hline The crowdsourcing platform & CrimeID: A web-based application for the crowdsourcing platform \\
\hline
\end{tabular}

As stated above, the crowd of the CrimeID is Indonesian citizens. The main task of the crowd is to annotate crime data according to the chosen category during registration and through the profile setting of the crowd. The annotation process of crime data is done by selecting available crime news, filling in the fields of data (Table 2) such as victim data, the perpetrator, and the crime location (Figure 3). The crowd can also report any improper annotation process of crime data conducted by other crowds. The process of checking the data validity is facilitated by always pairing the news of crime with data annotation results conducted by the crowd. It aims to maintain the data validity of the data input by the crowd. All the crowd activity is performed using the crowdsourcing platform (https://alert.id/crime) to assist the annotation of crime data from published crime news. The set of data that already processed in this system when this article was written is shown in Table 3.

Table 2. The List of Crime Data to Identify by the Crowd

\begin{tabular}{|l|}
\hline Crime Event \\
Date occurred (yyyy-mm-dd) \\
Time occurred (dd:mm:ss) \\
\hline Crime Location \\
Address \\
Province \\
Sub-Province \\
District \\
Sub-District \\
\hline Crime Victim \\
Victim Name \\
Numbers of Victims \\
Numbers of Child Victims \\
Numbers of Adult Victims \\
Numbers of Male Victims \\
Numbers of Female Victims \\
\hline Crime Suspect and Status \\
Suspect Name \\
Crime Status \\
\hline
\end{tabular}




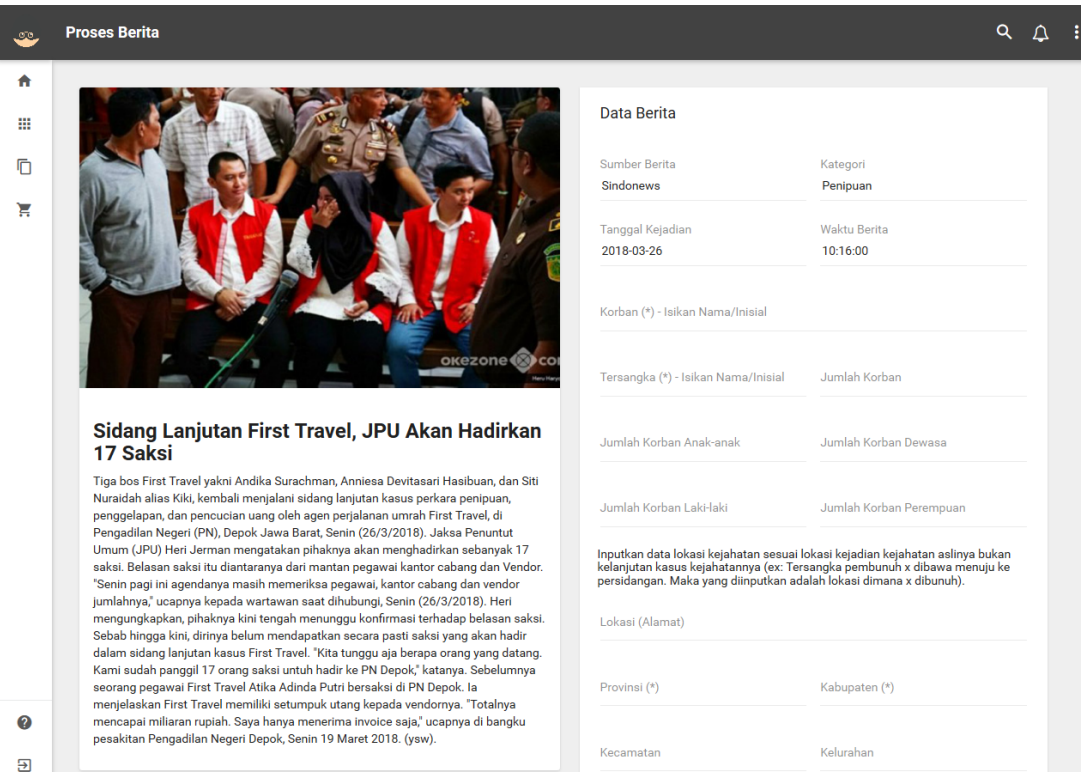

Fig. 3. Webpage for Annotation Process

Table 3. Summary of The Processed Crime Data

\begin{tabular}{|l|c|}
\hline Total of News Article & 5387 \\
\hline Amount of Processed News Article & 3012 \\
\hline Amount of Inprocessed News Article & 539 \\
\hline Amount of Unprocessed News Article & 1836 \\
\hline Number of Data Related to Murder & 1300 \\
\hline Amount Number of Data Related to Theft & 919 \\
\hline Amount Number of Data Related to Harassment & 257 \\
\hline Amount of Data Related to Sexual Harassment & 568 \\
\hline Amount of Data Related to Pickpocketing & 12 \\
\hline Amount of Data Related to Kidnapping & 155 \\
\hline Amount of Data Related to Persecution & 810 \\
\hline Amount of Data Related to Fraud & 374 \\
\hline Amount of Data Related to Mugging & 161 \\
\hline Amount of Data Related to Moping & 36 \\
\hline Amount of Data Related to Robbery & 654 \\
\hline Amount of Data Related to Rape & 148 \\
\hline
\end{tabular}

\subsection{Developing the gamification mechanism for the crowdsourcing platform}

The CrimeID crowdsourcing platform implements the concept of gamification based on the MDA framework which stands for Mechanics, Dynamics and Aesthetics [16]. This gamification is used to fulfill the incentive element which is the new pillar mentioned in integrated crowdsourcing definition [17]. In CrimeID, we just used the mechanics aspect by using challenge, leaderboard, level, and redeem points in the form of a virtual gift as the mechanics' element. 
The challenge given is the task of annotating crime news data and reporting irregularities to the results of annotated data. Users will get additional points when annotating crime news data or reporting any unusual things found in annotated data. Users will get a point deduction if it is proven that they submitted invalid data. Points that have been collected will serve as the basis for compiling a list of leaderboards (Figure 4) and level ups that can be used to purchase a virtual gift in the form of an avatar in accordance with the level achieved (Figure 5).

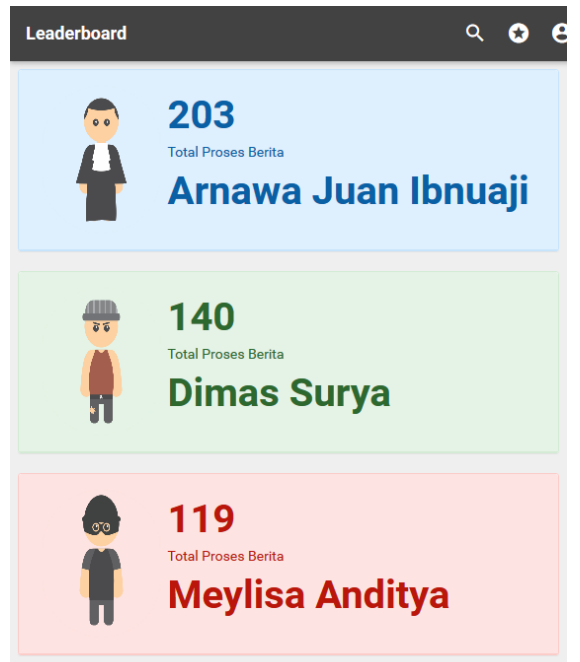

Fig. 4. Webpage for Leaderboard as One of the Gamification Implementation

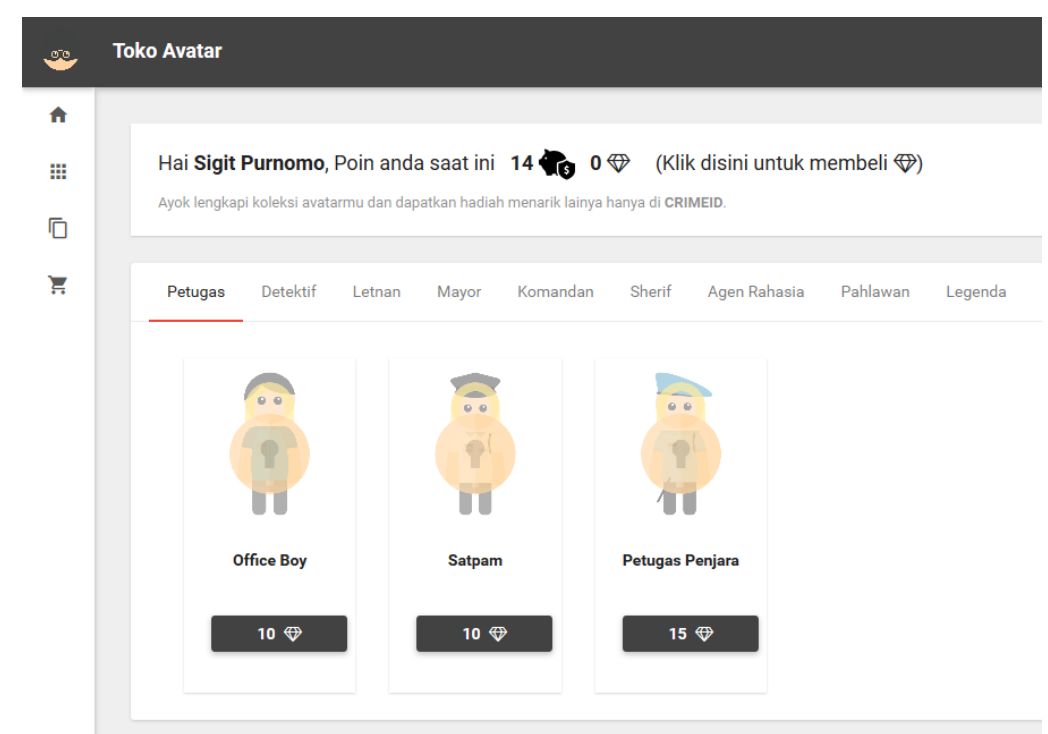

Fig. 5. Webpage for Virtual Badge Store as one of Gamification Implementation 


\subsection{Supporting crime prevention and community safety using crimeID}

Data that has been processed through the crowdsourcing platform can be accessed by the other parties through an application programming interface. Parties that need the crime data can register to the open data services to gain an access. Existing data may be used by that parties to develop applications in accordance with the needs of third parties. It is intended that the existing data can be utilized properly for crime prevention and community safety program.

CrimeID also consists of a mobile location-aware system named Crime Alert (Android $^{1}$ and IOS Version ${ }^{2}$ ). This app has four main features. First, a feature to provide alerts when a user enters an area and to check whether the region is prone to crime or not (Figure 6). Second, a feature to view crime news taken from an online news site (Figure 7). Third, the feature to display crime statistics both by crime category and the area of the crime occurrences (Figure 8). Fourth, the feature to perform the process of crime data annotation based on news of crime that both have already existed and not in the system (Figure 9). This feature is similar to the one on the Web-based crowdsourcing service platform.

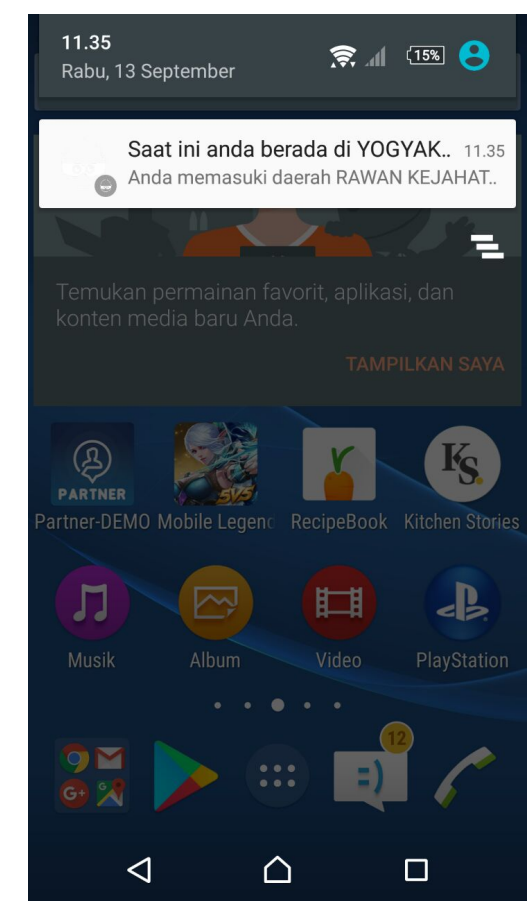

Fig. 6. Alert Notification

\footnotetext{
${ }^{1}$ https://play.google.com/store/apps/details?id=com.crime.alert\&hl=en

${ }^{2}$ https://itunes.apple.com/us/app/crime-alert/id1315403754?mt=8
} 


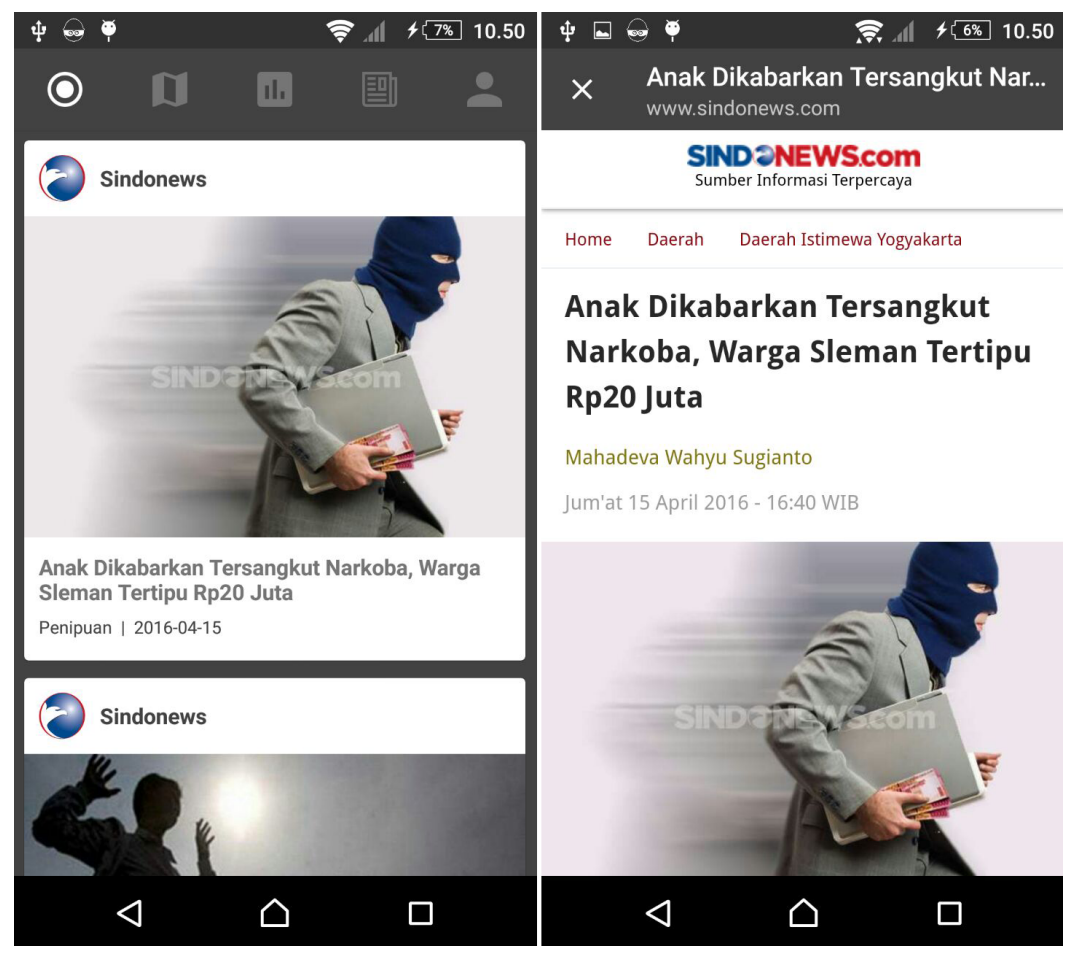

Fig. 7. News Article Feature from the Mobile Application

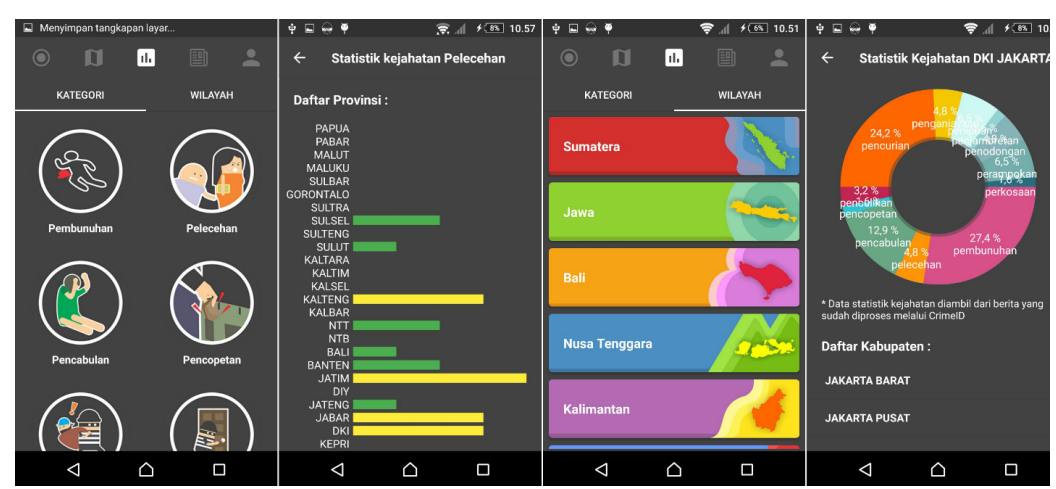

Fig. 8. Crime Statistic Feature of Mobile Application 


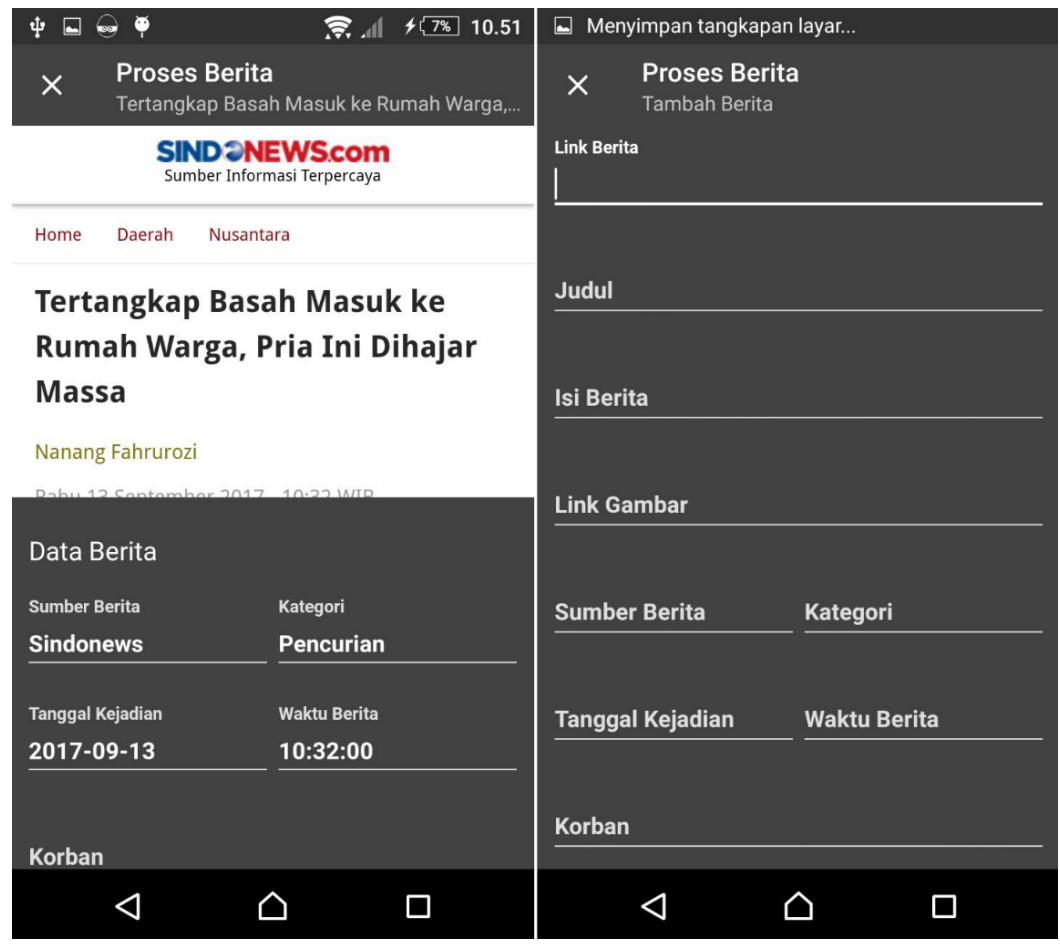

Fig. 9. Annotation Feature in the Mobile Application

This location-aware system is expected to help citizen finding information about crimes that occurred in Indonesia. With such information, it is hoped that the citizen will be more aware of the possibility of crime, related to possible time and location. The information that is always updated can help to prevent crime. Citizens who are vulnerable to crime can change their behavior after receiving an alert for the crime occurrence for example by avoiding the location of the crime [18]. Users will get notifications or alerts when entering a crime-prone area. The citizen can also obtain information about criminal acts that exist in both the news about crime and crime statistics based on its category and the area. Users can also be actively involved in updating data through a crowdsourcing feature to perform crime data annotations or crime reposting [19]. In the end, this system is expected to help prevent the occurrence of crime and improve the security in society.

\section{Discussion}

The sets and quality of the data are very important towards the crime prevention and safety in community. From our observation during the implementation of CrimeID, the growth of the annotated data was very slow. We identified that one of the main problems is how to gather the crowd because this is a voluntary crowd system [14]. To address this problem, we requested the participation of the students that 
took Introduction to Informatics (Computer Science) classes as part of their class assignments.

In 2017/2018 academic year, we give each student (approximately 120 students) a task to annotate at least 10 news articles to get the maximum grade. In the 2018/2019 academic year, we design a little modification in the experiment. The experiment is still part of the class assignment with 54 students but with different scenario as shown in Table 4. Both experiments show that the set of annotated data grow significantly.

Table 4. The Experiment Scenario for 2018/2019 Academic Year

\begin{tabular}{|c|c|}
\hline Number of News Article Processed & Assignment Grade \\
\hline Below 10 & 50 \\
\hline $11-20$ & 60 \\
\hline $21-30$ & 70 \\
\hline $31-40$ & 80 \\
\hline $41-50$ & 90 \\
\hline Above 50 & 100 \\
\hline
\end{tabular}

Another problem is the user participation performance. It should be identify by demographics, financial incentives, intrinsic incentives, and worker behavior [20]. From our experiments, the demographics of the users are just students. As a student, his or her motivation and behavior were affected by the grade. The gamification, especially the badge and virtual gifts, did not influence the students to work more tasks, especially after the assignment due date had been passed. There are just little students who did an extraordinary behavior by annotating more news articles than required. Most of the student's motivation was just to get the maximum grade in their assignment that was very important for them, especially if there were no financial incentives in this system.

Both of the data growth and user participation performance problem could be overcome by using the latest technology to automate the annotations process. Technology like natural language processing, machine learning or deep learning could be used to extract the crime information from text [21] [22]. The annotation pipeline's process also could be done automatically and the crowd just execute the annotation using the simple user interaction [23].

\section{Threats to Validity}

The proposed solution (CrimeID) still have some weaknesses. First, it is related to gamification. The system will be only attractive to young people. Adults or the elderly would not be interested in this kind of incentive. Second, it is related to the validity of the data. The system used online news article as the source of the data, but it requires a certain education level for annotating the data. When the crowd doesn't have suitable skill in reading, writing, and understanding the article, it can be a potential source for errors or invalid data. 


\section{Conclusion and Future Works}

The CrimeID system could help the crime prevention and community safety efforts in Indonesia. The citizen could participate individually to join the crowdsourcing platform as a crowd that will help to annotate the crime data from a news article. Gamification concept that implemented in the crowdsourcing platform would hopefully attract more citizens to participate in this platform. The collected crime data would be useful to raise awareness among the community members about the risk level of the population exposed to crime. The future works could develop the automatic annotation process using a machine learning model that is trained from the annotated data.

\section{Acknowledgement}

The authors gratefully thank the Indonesian's Directorate General of Research and Development Strengthening, Ministry of Research, Technology and Higher Education who funded this research for two years. The authors also give thanks to all of the parties who support this research and publications.

\section{References}

[1] Central Bureau of Statistics, "Criminal Statistics 2016," Central Bureau of Statistics, Jakarta, 2016.

[2] President of Republic Indonesia, "Law Of The Republic Of Indonesia Number 2 Of 2002 about Police Of The Republic Of Indonesia," 8 January 2002. [Online]. Available: http://peraturan.go.id/inc/view/11e44c4e34add60089d9313231323330.html. [Accessed 25 September 2018].

[3] Indonesia State Police, "Police Chief Regulation Number 23 of 2007 about Neighborhood Security System," 2007. [Online]. Available: http://ditlantas.sumut.polri.go.id/main/showattachment/68. [Accessed 25 September 2018].

[4] J. Byrne and G. Marx, "Technological Innovations in Crime Prevention and Policing. A Review of the Research on Implementation and Impact," Journal of Police Studies, vol. 3, no. 20, pp. 17-40, 2011.

[5] B. C Welsh and D. P. Farrington, Crime Prevention Effects of Closed Circuit Television: A Systematic Review, London: Home Office, 2002.

[6] B. C. Welsh and D. P. Farrington, "Crime Prevention and Hard Technology: The Case of CCTV and Improved Street Lighting," in The New Technology of Crime, Law and Social Control, J. M. B. a. D. J. Rebovich, Ed., New York, Criminal Justice Press, 2007, pp. 81102. https://doi.org/10.1093/acprof:oso/9780195326215.003.0006

[7] A. Hankin, M. F. Hertz and T. Simon, "Impacts of metal detector use in schools: insights from 15 years of research," The Journal of School Health, vol. 81, no. 2, pp. 100-106, 2011. https://doi.org/10.1111/j.1746-1561.2010.00566.x

[8] T.-H. Moon, S.-Y. Heo and S.-H. Lee, "Ubiquitous Crime Prevention System (UCPS) for a Safer City," Procedia Environmental Sciences, vol. 22, pp. 288-301, 2014. https://doi. org/10.1016/j.proenv.2014.11.028 
[9] S. Rahim, S. Tie, . A. Begum and B. Naz, "ICTs based crime control model: An application based study of Gilgit-Baltistan, Pakistan," Chengdu, 2011. https://doi.org/10.1109/ icemi.2011.6037753

[10] S. Kasim, H. Hafit, N. P. Yee, R. Hashim, H. Ruslai, K. Jahid and M. S. Arshad, "CMIS: Crime Map Information System for Safety Environment," Melaka, 2016. https://doi.org/10. $\underline{1088 / 1757-899 x / 160 / 1 / 012096}$

[11] T. Bjørgo, Preventing Crime: A Holistic Approach, 1 ed., Palgrave Macmillan UK, 2016.

[12] J. V. Roberts and R. Hastings, "Public Opinion and Crime Prevention: A Review of International Trends," in The Oxford Handbook of Crime Prevention, D. P. F. a. B. C. Welsh, Ed., New York, Oxford University Press, 2012, pp. 488-507. https://doi.org/10.1093/ oxfordhb/9780195398823.013.0024

[13] A. Madero-Hernandez, B. S. Fisher and P. Wilcox, "Exploring the overlap between individualistic and collective crime prevention," Crime Prevention and Community Safety, vol. 18, no. 4, p. 245-265, 2016. https://doi.org/10.1057/s41300-016-0007-y

[14] R. M. Borromeo and M. Toyama, "An investigation of unpaid crowdsourcing," Humancentric Computing and Information Sciences, vol. 6, no. 11, pp. 2-19, 2016. https://doi.org/ 10.1186/s13673-016-0068-z

[15] M. Hosseini, K. Phalp, J. Taylor and R. Ali, "The four pillars of crowdsourcing: A reference model," Marrakech, 2014.

[16] G. Zichermann and C. Cunningham, Gamification by Design, O'Reilly Media, 2011.

[17] E. Estellés-Arolas and F. González-Ladrón-de-Guevara, "Towards an integrated crowdsourcing definition," Journal of Information Science, vol. 38, no. 2, pp. 189-200 , 2012. https://doi.org/10.1177/0165551512437638

[18] J. Blom, D. Viswanathan, M. Spasojevic, J. Go, K. Acharya and R. Ahonius, "Fear and the City - Role of Mobile Services in Harnessing Safety and Security in Urban Use Contexts," Atlanta, 2010. https://doi.org/10.1145/1753326.1753602

[19] E. Tan, H. Xia, C. Ji, R. V. Joshi and Y. Huang, "Designing a Mobile Crowdsourcing System for Campus Safety," California, 2015.

[20] M.-C. Yuen, I. King and K.-S. Leung, "A Survey of Crowdsourcing Systems," Boston, 2011.

[21] V. Pinheiro, V. Furtado, T. Pequeno and D. Nogueira, "Natural Language Processing based on Semantic inferentialism for extracting crime information from text," Vancouver, 2010. $\underline{\text { https://doi.org/10.1109/isi.2010.5484783 }}$

[22] R. Arulanandam, B. T. R. Savarimuthu and M. A. Purvis, "Extracting crime information from online newspaper articles," Auckland, 2014.

[23] E. Pavlick and C. Callison-Burch, "The Gun Violence Database," New York City, 2016.

[24] P. Vora, M. Khara and K. Kelkar, "Classification of Tweets based on Emotions using Word Embedding and Random Forest Classifiers," International Journal of Computer Applications, pp. 1-7, 2017. https://doi.org/10.5120/ijca2017915773

[25] V. Sintsova, C. Musat and P. Pu, "Semi-Supervised Method for Multi-Category Emotion Recognition in Tweets," in IEEE International Conference on Data Mining Workshop, Shenzhen, 2014. https://doi.org/10.1109/icdmw.2014.146

[26] B. Resch, A. Summa, P. Zeile and M. Strube, "Citizen-Centric Urban Planning through Extracting Emotion Information from Twitter in an Interdisciplinary Space-TimeLinguistics Algorithm," Urban Planning 1, pp. 114-127, 2016. https://doi.org/10.17645/ up.v1i2.617

[27] M. Hasan, E. Rundensteiner and E. Agu, "Automatic emotion detection in text streams by analyzing Twitter data," International Journal of Data Science and Analytics, pp. 1-17, 2018. https://doi.org/10.1007/s41060-018-0096-Z 
[28] J. Effendi The, A. Farizki Wicaksono and M. Adriani, "A two-stage emotion detection on Indonesian tweets," in 2015 International Conference on Advanced Computer Science and Information Systems (ICACSIS) , Depok, Indonesia, 2015. https://doi.org/10.1109/ icacsis.2015.7415174

[29] L. F. S. Coletta, N. F. F. da Silva, E. R. Hruschka and E. R. Hruschka Jr., "Combining Classification and Clustering for Tweet," in Brazilian Conference on Intelligent Systems, São Carlos, 2014. https://doi.org/10.1109/bracis.2014.46

[30] R. M. Cahyaningtyas, R. Kusumaningrum, S. S. and D. E. Riyanto, "Emotion Detection of Tweets in Indonesian Language Using LDA and Expression Symbol Conversion," in International Conference on Informatics and Computational Sciences, Semarang, 2017. https://doi.org/10.1109/icicos.2017.8276371

[31] M. S. Asriadie, M. S. Mubarok and A., "Classifying emotion in Twitter using Bayesian network," Journal of Physics: Conference Series, pp. 1-14, 2018. https://doi.org/10.1088/ 1742-6596/971/1/012041

[32] A. Almehmadi, M. Bourque and K. El-Khatib, "A Tweet of the Mind: Automated Emotion Detection for Social Media Using Brainwave Pattern An," in Proceedings - SocialCom/PASSAT/BigData/EconCom/BioMedCom 2013, Washington, D.C., 2013. https://doi.org/10.1109/socialcom.2013.158

\section{Authors}

Yohanes Sigit Purnomo W.P. is a lecturer at Informatics Department, Faculty of Industrial Technology, Universitas Atma Jaya Yogyakarta. He has more than 18 years of teaching experience. He received his M.Kom. from Universitas Indonesia, Indonesia. His research interests include platform-based development, machine learning, natural language processing, and social media analysis.

Theresia Devi Indriasari is a lecturer in Informatics Department at Universitas Atma Jaya Yogyakarta, Indonesia. She has more than 16 years of teaching experience. She received her M.Sc. from RWTH University, Germany. Her research interests are mobile computing, social network analysis, human computer interaction, Internet of Things, and disaster management.

Kusworo Anindito is a lecturer in Informatics Department at Universitas Atma Jaya Yogyakarta, Indonesia. He has more than 20 years of teaching experience. He received his Master of Engineering from Institut Teknologi Bandung, Indonesia. His research interest are mobile and web application, computer network, and disaster management.

Yoshua Andrean was student in Informatics Department at Universitas Atma Jaya Yogyakarta. He received his bachelor degree in 2016 and now he work as product engineer at GOJEK.

Jaka Galih Prasetyo was student in Informatics Department at Universitas Atma Jaya Yogyakarta. He received his bachelor degree in 2016 and now he work as programmer at Information System Office Universitas Atma Jaya Yogyakarta.

Article submitted 2019-01-17. Resubmitted 2019-05-30. Final acceptance 2019-05-30. Final version published as submitted by the authors. 